\title{
Penetration loss of Walls and data rate of IEEE802.16m WiMAX
}

\author{
Hala BahyEldeen Nafea, Fayez W. Zaki, Hossam E. S. Moustafa \\ Dept. of Electronics and Communications Eng, Faculty of Engineering, Mansoura University, Egypt
}

Email address:

eg_hala2007@yahoo.com (H. B. Nafea)

\section{To cite this article:}

Hala BahyEldeen Nafea, Fayez W. Zaki, Hossam E. S. Moustafa. Penetration Loss of Walls and Data Rate of IEEE802.16m WiMAX. International Journal of Wireless Communications and Mobile Computing. Vol. 2, No. 1, 2014, pp. 1-10. doi: $10.11648 /$ j.wcmc.20140201.11

\begin{abstract}
In this paper, the data rate for the downlink (DL) of OFDMA-based IEEE802.16m WiMAX system and the available DL throughput as a function of distance to the Base Station (BS) are estimated for a number of propagation scenarios (OUTDOOR; INDOOR 1, INDOOR 2 and INDOOR 3). Moreover, Walls penetration loss is also considered. Adaptive modulation and Coding (AMC) schemes will be assumed in the present study for $5 \mathrm{MHz}$ and $20 \mathrm{MHz}$ channel bandwidth.
\end{abstract}

Keywords: WiMAX, Broadband Wireless, Adaptive Modulation and Coding, Propagation Analysis

\section{Introduction}

One of the newest technologies, that satisfy the ongoing demand for faster data rates with longer transmission ranges and that are thus suitable for new applications is mobile WiMAX. Mobile WiMAX will compete with cellular, Wi-Fi, and last-mile Internet access technologies such as DSL and cable.

The next generation of mobile WiMAX is IEEE $802.16 \mathrm{~m}$ amends the IEEE 802.16e, $\mathrm{j}$ specification to provide an advanced air interface for operation in licensed bands. It is a recommended candidate for $4 \mathrm{G}$. Unlike other wireless standards, WiMAX allows data transport over multiple broad frequency ranges. This lets the technology avoid frequencies that would interfere with other wireless applications.

Pushed by the increasing market demand for wireless wideband services, strong industry support and a competitive edge over deployed 3.5G systems Orthogonal Frequency Division Multiple Access (OFDMA) based Mobile WiMAX is on the verge of becoming a reality all over the globe [1].

In this paper, a preliminary analysis of the data rate as a function of the distance of the subscriber station (SS) to the BS is developed, considering different propagation environments and $3.5 \mathrm{GHz}$ carrier frequency.

\section{System Parameters}

\subsection{Frequency Bands}

Considering the 3.3-3.8 GHz spectrum, the WiMAX Forum $^{\mathrm{TM}}$ Mobile System Profile [2] specifies the channel bandwidth combinations, Fast Fourier Transform (FFT) sizes and duplexing modes as shown in Table 1, for the possible frequency range configurations.

Table 1. Possible WiMAX configurations for the 3.3-3.8 GHz band [2]

\begin{tabular}{llll}
\hline $\begin{array}{l}\text { Frequency } \\
\text { Range } \\
\text { (GHz) }\end{array}$ & $\begin{array}{l}\text { Channel } \\
\text { Bandwidth } \\
(\mathbf{M H z} \mid)\end{array}$ & $\begin{array}{l}\text { FFT } \\
\text { Size }\end{array}$ & $\begin{array}{l}\text { Duplexing } \\
\text { Mode }\end{array}$ \\
\hline & 5 & 512 & TDD \\
$3.3-3.4$ & 7 & 1024 & TDD \\
& 10 & 1024 & TDD \\
$3.4-3.8$ & 5 & 512 & TDD \\
& 7 & 1024 & TDD \\
& 10 & 1024 & TDD \\
$3.4-3.6$ & 5 & 512 & TDD \\
& 7 & 1024 & TDD \\
& 10 & 1024 & TDD \\
$3.6-3.8$ & 5 & 512 & TDD \\
& 7 & 1024 & TDD \\
\hline
\end{tabular}

\subsection{OFDMA Parameters}

OFDMA is a multiple access technique which divides 
the total Fast Fourier Transform (FFT) space into a number of sub-channels (set of sub-carriers that are assigned for data exchange) whereas the time resource is divided into time slots (i.e. in WiMAX OFDMA PHY [3], the minimum frequency time unit of sub-channel is one slot, which is equivalent to 48 sub-carriers) and a frame is constructed from number of slots. Define the size of FFT as NFFT which denotes the total number of sub-carriers of all types (pilots, guard and data). Let Ndata denote the total number of data sub-carriers after reserving the pilot and guard subcarriers. Ndata is divided into $\mathrm{L}$ groups, each with $\mathrm{K}=$ Ndata/L data sub-carriers.

For the possible channel bandwidth, Table 2 summarizes the standard IEEE 802.16 OFDMA parameters.

Table 2. OFDMA Parameters [11]

\begin{tabular}{|c|c|c|c|c|c|}
\hline \multirow{2}{*}{$\begin{array}{l}\text { Parameter } \\
\text { FFT Size }\end{array}$} & \multirow{2}{*}{$\begin{array}{l}\text { Fixed } \\
\text { WiMAX } \\
\text { OFDM-PHY } \\
256\end{array}$} & \multicolumn{4}{|c|}{$\begin{array}{l}\text { Mobile WiMAX Scalable } \\
\text { OFDMA-PHY }\end{array}$} \\
\hline & & 128 & 512 & 1024 & 2048 \\
\hline Number of used data subcarriers & 192 & 72 & 360 & 720 & 1440 \\
\hline Number of pilot data subcarriers & 8 & 12 & 60 & 120 & 240 \\
\hline $\begin{array}{l}\text { Number of null/guard band data } \\
\text { subcarriers }\end{array}$ & 56 & 44 & 92 & 184 & 368 \\
\hline Cyclic prefix of guard time ( $\mathrm{Tg} / \mathrm{Tb})$ & \multicolumn{5}{|c|}{$1 / 32,1 / 16,1 / 8,1 / 4$} \\
\hline Oversampling rate (Fs/BW) & \multicolumn{5}{|c|}{$\begin{array}{l}\text { Depends on bandwidth:7/6 for } 256 \mathrm{OFDM}, 8 / 7 \text { for multiples of } 1.75 \mathrm{MHz} \text {, and } 28 / 25 \text { for multiples of } 1.25 \\
\mathrm{MHz}, 1.5 \mathrm{MHz}, 2 \mathrm{MHz} \text {, or } 2.75 \mathrm{MHz}\end{array}$} \\
\hline Channel bandwidth (MHz) & 3.5 & 1.25 & 5 & 10 & 20 \\
\hline Subcarrier frequency spacing $(\mathrm{KHz})$ & 15.625 & 10.94 & & & \\
\hline Useful symbol time ( $\mu \mathrm{s})$ & 64 & 91.4 & & & \\
\hline Guard time assuming $12.5 \%(\mu \mathrm{s})$ & 8 & 11.4 & & & \\
\hline OFDM symbol duration $(\mu \mathrm{s})$ & 72 & 102.9 & & & \\
\hline $\begin{array}{l}\text { Number of OFDM symbols in } 5 \mathrm{~ms} \\
\text { frame }\end{array}$ & 69 & 48.0 & & & \\
\hline
\end{tabular}

In the present study a frame duration of $5 \mathrm{~ms}$ has been assumed, since, at least initially all WiMAX equipments will only support this duration.

\subsection{Frame and Subchannel Structure}

The 802.16e PHY [3] supports TDD, FDD; however the initial release of Mobile WiMAX certification profiles is includes only TDD. With ongoing releases, FDD profiles is considered by the WiMAX Forum to address specific market opportunities where local spectrum regulatory requirements either prohibit TDD or are more suitable for FDD deployments. To counter interference issues, TDD does require system-wide synchronization; nevertheless.

One should note that the first system profiles released by the WiMAX Forum only contemplate time division duplexing (TDD) modes, due to a number of advantages over frequency division duplexing (FDD). TDD is the preferred duplexing mode for the following reasons:

i. TDD enables adjustment of the DL/ UL ratio to efficiently support asymmetric downlink/uplink traffic, while with FDD, downlink and uplink always have fixed (and most times equal) and generally, equal DL and UL bandwidths.

ii. TDD assures channel reciprocity because the DL and UL frames are sent in the same band, for better support of link adaptation, MIMO, and other closed loop advanced antenna technologies (AAS).

iii. Unlike FDD, which requires a pair of channels, TDD only requires a single channel for both downlink and uplink providing greater flexibility for adaptation to varied global spectrum allocations.

iv. Transceivers design for TDD implementations are less complex and therefore less expensive.

Figure 1 illustrates the OFDM frame structure for a Time Division Duplex (TDD) implementation. Each frame is divided into DL and UL sub-frames separated by Transmit/Receive and Receive/Transmit Transition Gaps (TTG and RTG, respectively) to prevent DL and UL transmission collisions. In a frame, the following control information is used to ensure optimal system operation:

1) Preamble: The preamble, used for synchronization, is the first OFDM symbol of the frame.

2) Frame Control Head (FCH): The FCH follows the preamble. It provides the frame configuration information such as MAP message length, coding scheme and usable sub-channels.

3) DL-MAP and UL-MAP: The DL-MAP and UL-MAP provide sub-channel allocation and other control information for the DL and UL sub-frames respectively.

4) UL Ranging: The UL ranging sub-channel is allocated for mobile stations (MS) to perform closed-loop time, frequency, and power adjustment as well as bandwidth Requests.

5) UL CQICH: The UL CQICH channel is allocated for the MS to feedback channel state information. 
6) UL ACK: The UL ACK is allocated for the MS to feedback DL HARQ acknowledgement.

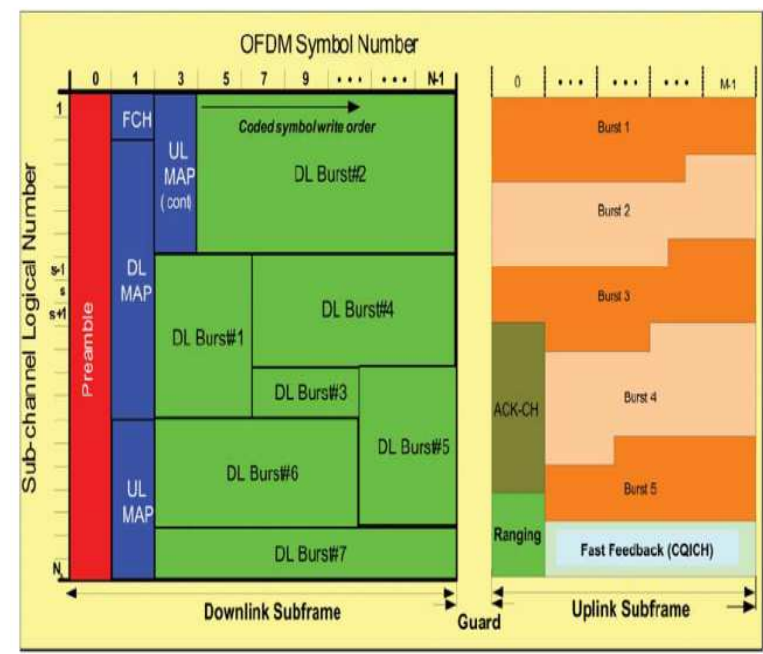

Figure 1. WiMAX OFDMA TDD Frame. (Extracted from [4])

The overheads in Figure1 have variable size depending on the type of traffic carried. In this analysis Full Buffer FTP traffic will be assumed, and a corresponding typical distribution of OFDMA symbols in the frame is shown in Table 3.

Table 3. TDD Frame configurations used [4].

\begin{tabular}{lllll}
\hline Parameter & \multicolumn{3}{l}{ Values } \\
\hline Channel bandwidth (MHz) & 5 & 10 & 7 \\
Number of OFDMA Symbols/Frame & 48 & 48 & 34 \\
Total Number of OFDMA Overhead Symbols & 10 & 10 & 7 \\
Number of OFDMA Symbols for TTG (guard) & 1 & 1 & 1 \\
Total Number of OFDMA Data Symbols & 37 & 37 & 26 \\
DL:UL $\quad \begin{array}{l}\text { DL OFDMA } \\
\text { Data Symbols } \\
\text { 3:1 }\end{array} \quad \begin{array}{llll}\text { UL OFDMA } \\
\text { Data Symbols }\end{array}$ & 9 & 9 & 7 \\
\hline
\end{tabular}

This option is somehow conservative, since most applications have a traffic which is bursty in nature and can operate efficiently with less overhead.

Moreover, as previously referred, TDD allows for flexible DL/UL ratios to cope with different traffic profiles. In this study a 3:1 DL: UL ratio will be analyzed, the respective data symbols distribution is also shown in Table 3.

IEEE 802.16 also allows different subcarrier permutations schemes, although the initial WiMAX system profile [5] only includes for the DL, Downlink Partial Usage of Subcarriers (DL PUSC) and Band Adaptive Modulation and Coding (Band AMC), with only the first being mandatory. Therefore, DL PUSC is considered as the subchannel permutation scheme. Table 4, shows the distribution of subcarriers for DL PUSC and UL PUSC mode.
Table 4. PUSC Parameters [11].

\begin{tabular}{lllll}
\hline Parameter & Downlink & UPlink & Downlink & UPlink \\
\hline $\begin{array}{l}\text { System bandwidth } \\
\text { (MHz) }\end{array}$ & 5 & & 10 & \\
FFT Size & 512 & & 1024 & \\
Null Sub-Carriers & 92 & 104 & 184 & 184 \\
Pilot Sub-Carriers & 60 & 136 & 120 & 280 \\
Data Sub-Carriers & 360 & 272 & 720 & 560 \\
Sub-Channels & 15 & 17 & 30 & 35 \\
Symbols Period, Ts & 102.9 microseconds & & \\
Frame Duration & 5 milliseconds & & \\
OFDM Symbols/ & 48 & & & \\
Frame & & & \\
Data OFDM & 44 & & \\
Symbols &
\end{tabular}

\subsection{Modulation and Coding Modes (Burst Profile)}

Adaptive modulation and coding (AMC), Hybrid Automatic Repeat Request (HARQ) and Fast Channel Feedback (CQICH) were introduced with Mobile WiMAX to enhance coverage and capacity for WiMAX in mobile applications.

Support for QPSK, 16QAM and 64QAM are mandatory in the DL with Mobile WiMAX. In the UL, 64QAM is optional. Both Convolutional Code (CC) and Convolutional Turbo Code (CTC) with variable code rate and repetition coding are supported. Block Turbo Code and Low Density Parity Check Code (LDPC) are supported as optional features.

Table 5, summarizes the coding and modulation schemes supported in the Mobile WiMAX profile.

Table 5. Supported Code and Modulations [11]

\begin{tabular}{llll}
\hline \multirow{2}{*}{ Modulation } & DL & UL \\
& & $\begin{array}{l}\text { QPSK,16QAM,64 } \\
\text { QAM }\end{array}$ & $\begin{array}{l}\text { QPSK, 16QAM, } \\
\text { 64QAM }\end{array}$ \\
\cline { 3 - 4 } Code & CC & $1 / 2,2 / 3,3 / 4,5 / 6$ & $1 / 2,2 / 3,5 / 6$ \\
Rate & CTC & $1 / 2,2 / 3,3 / 4,5 / 6$ & $1 / 2,2 / 3,5 / 6$ \\
& Repeteition & $\mathrm{X} 2, \mathrm{X} 4, \mathrm{X} 6$ & $\mathrm{X} 2, \mathrm{X} 4, \mathrm{X} 6$ \\
\hline
\end{tabular}

From several burst profiles allowed by IEEE 802.16, the six listed in Table 6 , along with the minimum required SNR, have been considered.

Table 6. SNR required for considered burst profiles. (CTC-Convolution Turbo Codes)

\begin{tabular}{cc}
\hline Burst Profile & SNR Required (d B) \\
\hline QPSK CTC 1/2 & 3.5 \\
QPSK CTC 3/4 & 6.5 \\
16- QAM CTC 1/2 & 9.0 \\
16- QAM CTC 3/4 & 12.5 \\
64- QAM CTC 2/3 & 16.5 \\
64- QAM CTC 3/4 & 18.5 \\
\hline
\end{tabular}




\subsection{Propagation Environments}

\subsubsection{Propagation Model}

Propagation models are used to estimate the Path loss (PL) value in wireless communications and to predict the level of SNR at the receiver. The PL value is used to determine the coverage of the base station and mobile station's cell-range.

The propagation model COST 231 Hata [6] has been adopted. Although this model is based on empirical data obtained at $2 \mathrm{GHz},[7]$ it is also valid model at $3.5 \mathrm{GHz}$.

\subsubsection{Penetration Loss}

Penetration will be modeled as an excess loss introduced by the penetrated walls, using the model suggested in [8]

$$
\begin{aligned}
& L_{e x}=L_{w i} k\left\lfloor\frac{k+1.5}{k+1}-b\right\rfloor[d B] \\
& b=-0.064+0.0705 L_{w i}-0.0018 L^{2}{ }_{w i}
\end{aligned}
$$

Where $\mathrm{L}_{\mathrm{wi}}$ is the average excess attenuation per wall and $\mathrm{k}$ is the number of penetrated walls. Table (7-a) shows the penetration loss $\left(\mathrm{L}_{\mathrm{wi}}\right)$ as a function of frequency for thin board dividing between rooms and thick walls made of reinforced concrete.

Table (7-a). Penetration loss as a function of frequency for two types of walls [9].

\begin{tabular}{lll}
\hline $\begin{array}{l}\text { Frequency } \\
\text { [GHz] }\end{array}$ & $\begin{array}{l}\text { Loss for thin } \\
\text { Walls[d B] }\end{array}$ & $\begin{array}{l}\text { Loss for thick } \\
\text { Walls[d B] }\end{array}$ \\
\hline 2 & 3.3 & 10.9 \\
3.5 & 3.4 & 11.4 \\
5 & 3.4 & 11.8 \\
\hline
\end{tabular}

Three indoor scenarios have then been considered. These are listed in Table (7-b) along with the respective attenuations calculated by equations (1) and (2) for a 3.5 $\mathrm{GHz}$ frequency. The chosen Indoor scenarios try to represent possible limiting situations on propagation. The analysis was limited to two walls, since when the number of walls increases, other propagation mechanisms become dominant.

Table (7-b). Penetration Loss Parameters.

\begin{tabular}{llll}
\hline Parameter & $\begin{array}{l}\text { Indoor1 } \\
\text { Thick Wall }\end{array}$ & $\begin{array}{l}\text { Indoor 2 Thick } \\
\text { Wall + Thin } \\
\text { Wall }\end{array}$ & $\begin{array}{l}\text { Indoor 3 2 } \\
\text { Thick Walls }\end{array}$ \\
\hline $\begin{array}{l}\text { Total Penetration } \\
\text { Loss [d B] }\end{array}$ & 11.4 & 12.9 & 18.0 \\
\hline
\end{tabular}

\subsubsection{Fading}

The diverse fading components due to the propagation environment will be taken into account in the form of propagation margins.

Table 8, illustrates the adopted margins and the total margin for the different considered scenarios. WiMAX Forum $^{\mathrm{TM}}$ reference studies have provided the guideline for this parameterization [10].

Table 8. Fading Margins Adopted.

\begin{tabular}{ll}
\hline \multicolumn{2}{c}{ Margin } \\
\hline Log Normal Fade Margin & $5.56 \mathrm{~dB}$ \\
Fast Fading Margin & $2.0 \mathrm{~dB}$ \\
Interference Margin & $2.0 \mathrm{~dB}$ \\
\hline
\end{tabular}

The value of $5.56 \mathrm{~dB}$ for the shadow fade margin is based on a log-normal shadowing standard deviation of 8 $\mathrm{dB}$ assuring a $75 \%$ coverage probability at the cell edge and $90 \%$ coverage probability over the entire area. The interference margin assumes a cellular reuse pattern of 1 with 3 sectors per site.

\subsection{Station Parameters}

Tables 9 presents the parameters used for the link budget calculations for the BS and SS, again based on WiMAX Forum $^{\mathrm{TM}}$ analysis [10].

\begin{tabular}{|c|c|c|c|c|c|}
\hline \multicolumn{3}{|c|}{ Base Station Parameters } & \multicolumn{3}{|c|}{ Subscriber Station Parameters } \\
\hline BS Height & $\mathrm{h}_{\mathrm{b}}$ & $32 \mathrm{~m}$ & Subscriber Station Height & $\mathrm{h}_{\mathrm{m}}$ & $1.5 \mathrm{~m}$ \\
\hline $\mathrm{T}_{\mathrm{x}}$ Power per Antenna Element & $\mathrm{P}_{\mathrm{E}}$ & $10 \mathrm{~W}$ & Number of $R_{x}$ Antenna Elements & & 2 \\
\hline Number of $T_{x}$ Antenna Elements & & 2 & Antenna Diversity Gain & $\mathrm{G}_{\mathrm{DW}}$ & $3 \mathrm{~dB}$ \\
\hline Cyclic Combining Gain & $\mathrm{G}_{\mathrm{CYC}}$ & $3 \mathrm{~dB}$ & $\mathrm{R}_{\mathrm{x}}$ Antenna Gain( Hand held Outdoor) & $\mathrm{G}_{\mathrm{R}}$ & $-1 \mathrm{dBi}$ \\
\hline $\mathrm{T}_{\mathrm{x}}$ Antenna Gain & $\mathrm{G}_{\mathrm{E}}$ & $15 \mathrm{dBi}$ & $\mathrm{R}_{\mathrm{x}}$ Antenna Gain(Fixed in door) & $\mathrm{G}_{\mathrm{R}}$ & $6 \mathrm{dBi}$ \\
\hline Pilot Power Boosting Attenuation & A PILOT & $-0.7 \mathrm{~dB}$ & Noise Figure & & $7 \mathrm{~dB}$ \\
\hline
\end{tabular}

Table 9. $B S$ and $S S$ the parameters

\section{Mathematical Analysis and Computer Simulation}

In order for the system to work correctly, the data rate in WiMAX can be calculated as:

$$
R=\frac{N_{u s e d} b_{m} c_{r}}{T_{S}}
$$

Where: $\mathrm{R}$ is the data rate in a WiMAX OFDM physical layer, $b_{m}$ is the number of bits per modulation symbol and 
is 1 for BPSK, 2 for QPSK, 4 for 16-QAM and in general if $\mathrm{M}$ is the modulation level in a M-QAM constellation, $\mathrm{M}=2^{\wedge} b_{m}$.The $c_{r}$ is the coding rate that can be found in [10, 11] for each different burst profile. The symbol duration $T_{S}$, $\mathrm{T}_{\mathrm{b}}$ is the useful symbol time, $\mathrm{T}_{\mathrm{g}}$ is the guard time according to Fig. 2, expressed as:

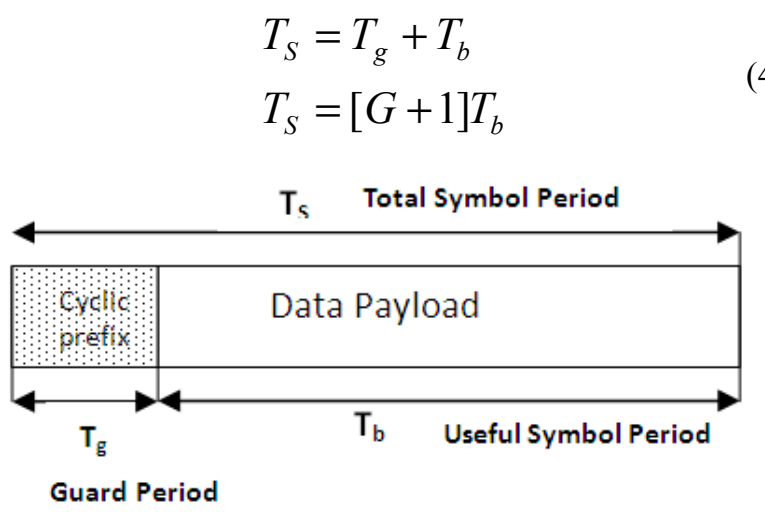

Fig. 2. OFDM Symbol Structure with Cyclic Prefix.

Where $\mathrm{G}$ is the ratio $T g / T b$, this value can be: $1 / 4,1 / 8,1 / 16$ or $1 / 32$. And $T b=1 / \Delta f$, with the sub-carrier spacing $\Delta f$ given as

$$
\begin{gathered}
\Delta f=\frac{F_{S}}{N_{F F T}} \\
F_{S}=\text { floor }(n B W / 8000) 8000
\end{gathered}
$$

Where $F_{S}$ is the sampling frequency, $n$ is the sampling factor, $B W$ is the nominal channel bandwidth. The sampling factor in conjunction with $B W$ value has changed from OFDMA 802.16-2004 Standard and is set to $8 / 7$ as follows: for channel bandwidths that are a multiple of 1.75 $\mathrm{MHz}$ then $n=8 / 7$ else for channel bandwidths that are a multiple of any of $1.25,1.5,2$ or $2.75 \mathrm{MHz}$ then $n=28 / 25$ else for channel bandwidths not otherwise specified then $n$ $=8 / 7$.

Sensitivity or minimum received power $S_{R}$ (receiver sensitivity) is different for each modulation and is expressed as [12]:

$S_{R}=-102+\operatorname{SNR}_{(R x)}+10 \log \left(F S \times\left(\frac{N_{\text {data }}}{N_{F F T}}\right) \times\left(\frac{N_{\text {subchannel } s}}{16}\right)\right)$

Equation (7-a) may be re-expressed as [11]:

$S_{R}=-114+S N R_{R x)}-10 \log R+10 \log \left(\frac{F_{S} N_{u s e d}}{N_{F F T}}\right)+\operatorname{ImpLosst} N F$ (7-b)

Where: $\mathrm{N}_{\mathrm{FFT}}$ is the number of points for FFT or total number of subcarriers. $N_{\text {data }}$ is number of used data subcarries, and $\mathrm{N}_{\text {subchannels }}$ is the number of subchannels. $\mathrm{N}_{\text {used }}$ (the active subcarriers = total subcarriers - null subcariers). ImpLoss is the implementation loss, which includes non-ideal receiver effects such as channel estimation errors, tracking errors, quantization errors, and phase noise. The assumed value is $7 \mathrm{~dB}$. NF is the receiver noise figure, referenced to the antenna port. The assumed value is $8 \mathrm{~dB}$, and $\mathrm{R}$ is the data rate in a WiMAX OFDM physical layer [13].

Tables 10, 11 present the different values of SR and Channel Capacity Cmodulation [bps] for each modulation at $5 \mathrm{MHZ}$ and $20 \mathrm{MHZ}$ bandwidth using SNR required for considered burst profiles. (CTC- Convolutional Turbo Codes).

Table 10. Receiver Sensitivity for Each Modulation Type at $5 M H Z$.

\begin{tabular}{cccc}
\hline Parameters & $\begin{array}{c}\text { SNR } \\
\text { (Rx) [d } \\
\text { B] }\end{array}$ & $\begin{array}{c}\text { RESICEVER } \\
\text { Sensitivity } \mathbf{S}_{\mathbf{R}} \\
{[\mathbf{~ d B ]}}\end{array}$ & $\begin{array}{c}\text { Usefull Channel } \\
\text { Capacity } \\
\text { Cmodulation } \\
\text { [bps] }\end{array}$ \\
\hline QPSK CTC 1/2 & 3.5 & -98.6561 & $4.0816 \mathrm{e}+006$ \\
QPSK CTC 3/4 & 6.5 & -97.4170 & $6.1224 \mathrm{e}+006$ \\
16-QAM CTC1/2 & 9.0 & -96.1664 & $8.1633 \mathrm{e}+006$ \\
16-QAM CTC 3/4 & 12.5 & -94.4273 & $1.2245 \mathrm{e}+007$ \\
64-QAM CTC 2/3 & 16.5 & -91.6767 & $1.6327 \mathrm{e}+007$ \\
64-QAM CTC 3/4 & 18.5 & -90.1883 & $1.8367 \mathrm{e}+007$ \\
\hline
\end{tabular}

The received power may be calculated using link budget equations given as:

$$
P_{R}=P_{T}+G_{T}+G_{R}-L_{S}-P L
$$

Where: $\mathrm{P}_{\mathrm{R}}$ is the received power, $\mathrm{P}_{\mathrm{T}}$ is the transmitted power, $G_{T}$ is the transmit antenna gain, $G_{R}$ is the receiver antenna gain, $\mathrm{L}_{\mathrm{S}}$ is the system loss and $\mathrm{P}_{\mathrm{L}}$ is the path loss.

PATHLOSS $=$ PT + GT + GR-PR-Lex

Table 11. Receiver Sensitivity for Each Modulation Type at 20MHZ [13].

\begin{tabular}{cccc}
\hline Parameters & $\begin{array}{c}\text { SNR } \\
\text { (Rx) } \\
\text { [dB] }\end{array}$ & $\begin{array}{c}\text { RESICEVER } \\
\text { Sensitivity } \mathbf{S}_{\mathbf{R}} \\
\text { [ dB] }\end{array}$ & $\begin{array}{c}\text { Usefull Channel } \\
\text { Capacity } \\
\text { Cmodulation [bps] }\end{array}$ \\
\hline QPSK CTC 1/2 & 3.5 & -98.6561 & $1.6327 \mathrm{e}+007$ \\
QPSK CTC 3/4 & 6.5 & -97.4170 & $2.4490 \mathrm{e}+007$ \\
16-QAM CTC 1/2 & 9.0 & -96.1664 & $3.2653 \mathrm{e}+007$ \\
16-QAM CTC 3/4 & 12.5 & -94.4273 & $4.8980 \mathrm{e}+007$ \\
64-QAM CTC 2/3 & 16.5 & -91.6767 & $6.5306 \mathrm{e}+007$ \\
64-QAM CTC 3/4 & 18.5 & -90.1883 & $7.3469 \mathrm{e}+007$ \\
\hline
\end{tabular}

\subsection{Cost-231 Hata Model}

In this model, five parameters are used for propagation loss estimation. These are frequency $\mathrm{f} \mathrm{MHz}$, distance from base station to mobile station $\mathrm{d}(\mathrm{Km})$, base station height $\mathrm{hb}(\mathrm{m})$, the height of the mobile $\mathrm{hm}(\mathrm{m})$, and standard deviation constant $\mathrm{Cm}(\mathrm{dB})$. The pass loss in Hata model is expressed as: 


$$
P L=463+339 \log _{0}(f)-13.82 \log _{0}\left(h_{b}\right)-a h_{m}-\left(449-6.55 \log _{0}\left(h_{b}\right)\right) \log _{0} d+C_{m}
$$

Where the parameters $\mathrm{Cm}$ and ahm are used to specify the environmental characteristics as given below: *Urban:

$$
C_{m}=3 d B a h_{m}=3.20\left(\log _{10}\left(11.75 h_{m}\right)\right)^{2}-4.97
$$

*Suburban/Rural:

$$
C_{m}=0 d B a h_{m}=\left(1.11 \log _{10} f-0.7\right) h_{m}-\left(1.56 \log _{10} f-0.8\right)
$$

Using the above equations, the relationship between the distance $\mathrm{d}$ and the propagation loss may be formulated as:

$$
d=10^{((\text {PATHLOSS-46.3-33.9*log } 10(\mathrm{f})+13.82 * \log 10(\mathrm{hb})+\mathrm{ahm}-\mathrm{cm}) /(44.9-6.55 * \log 10(\mathrm{hb})))}
$$

Where the PATHLOSS is calculated using Equation (9).

The simulation parameters are shown in Tables $7,8,9$. Four propagation scenarios (OUTDOOR; INDOOR 1, INDOOR 2 and INDOOR 3) are considered.

The SNR $(\mathrm{Rx})[\mathrm{dB}]$ and useful channel capacity $(\mathrm{C}$ modulation) for each modulation at $5 \mathrm{MHZ}$ and $20 \mathrm{MHZ}$ bandwidth shown in Tables 10, 11 are considered too.

The variation of the DL data rate as a function of the distance to the BS has been computed for the $5 \mathrm{MHz}$ and $20 \mathrm{MHz}$ bandwidth and are shown in Figure 3 and Figure 4 .

The maximum distance to $\mathrm{BS}$ for each modulation scheme in the four propagation scenarios (OUTDOOR; INDOOR 1, INDOOR 2 and INDOOR 3), for both urban and suburban at frequency band $3.5 \mathrm{GHZ}$, are shown in Tables12-15.

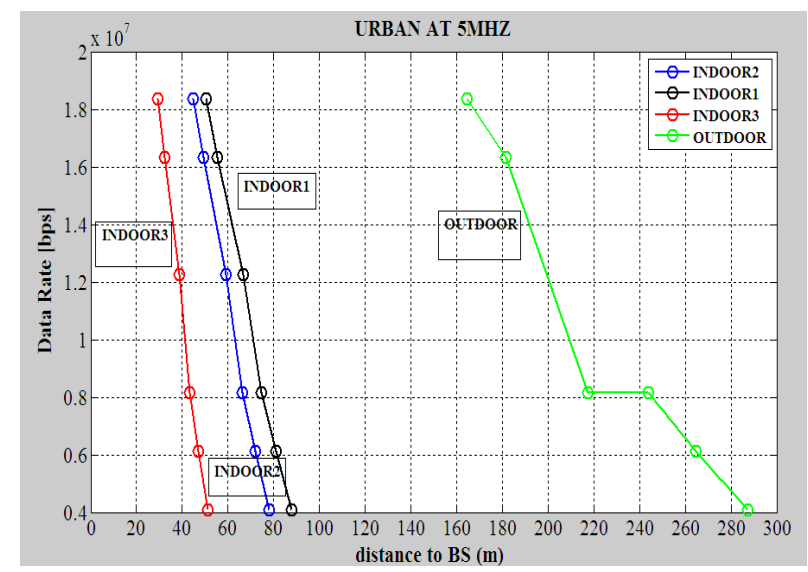

Figure 3 (a). $R$ (Data Rate) with distance to the BS for COSTHATA Urban at (5MHZ)

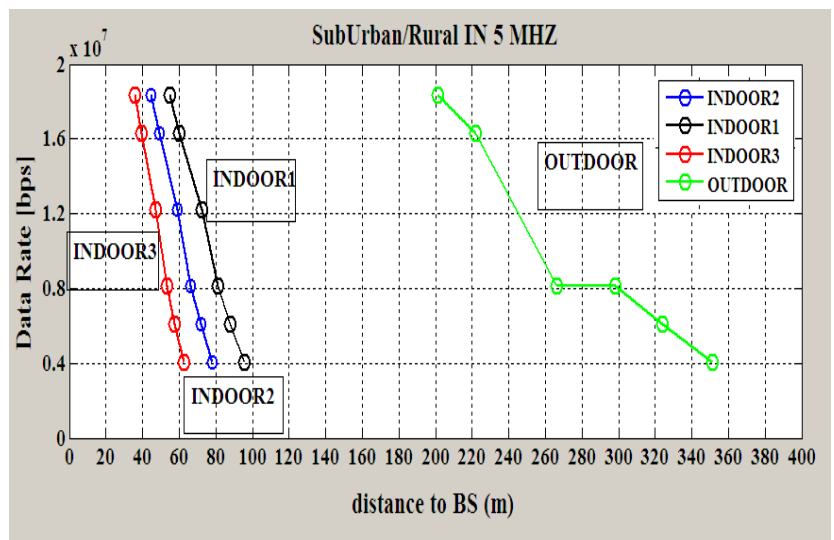

Figure 3 (b). $R$ (Data Rate) with distance to the BS for COSTHATA SubUrban at (5MHZ)

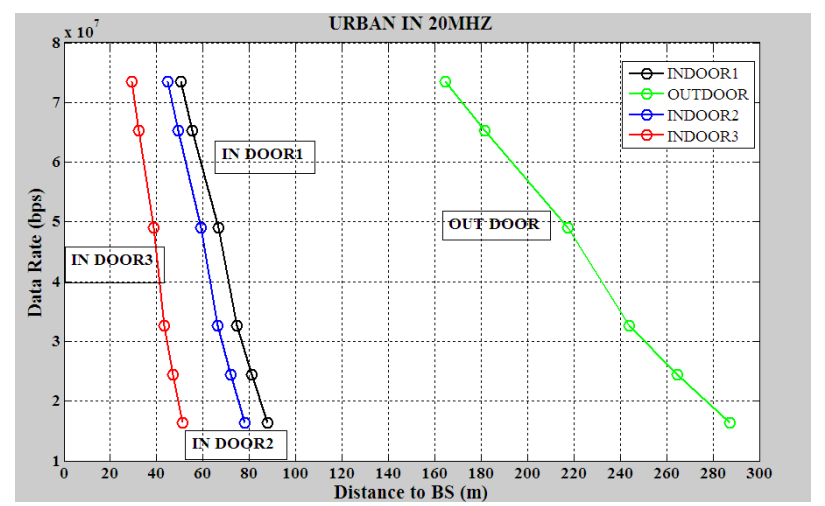

Figure 4 (a). $R$ (Data Rate) with distance to the BS for COSTHATA Urban at (20MHZ) 


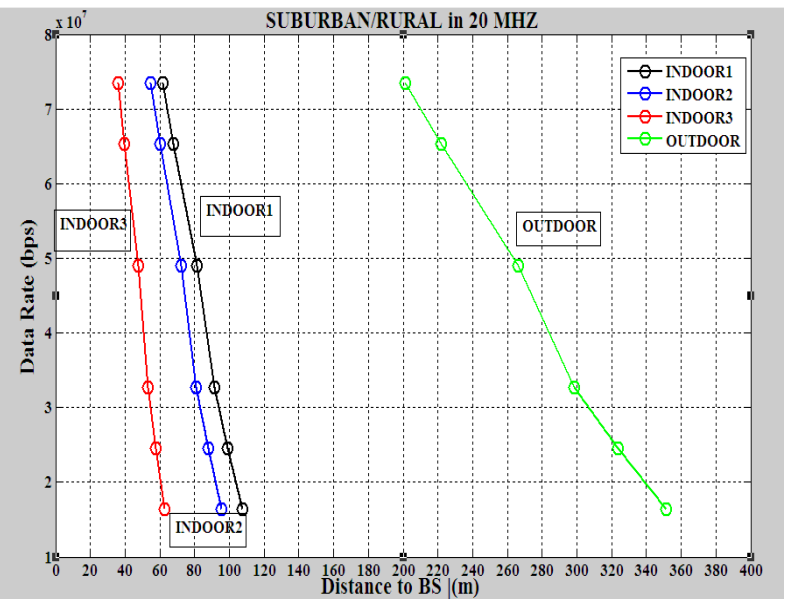

Figure 4 (b). $R$ (Data Rate) with distance to the BS for COSTHATA Suburban at (20MHZ)

The results in figures 3 and 4 showed that the maximum distance to base station in the suburban case is increased by $22 \%, 22.3 \%, 22.5 \%$, and $18.5 \%$ for INDOOR1, INDOOR 2 , INDOOR3, and OUTDOOR respectively as compared to the urban case.

Comparing OUTDOOR, INDOOR1, INDOOR 2 and INDOOR 3 scenarios, it is observed that the maximum distance to base station for INDOOR 2 is increased by $34.4 \%$ more than INDOOR 3, whereas this distance is increase by $11.3 \%$ for INDOOR1 as compared to INDOOR2. On the other hand without any Penetration Loss in OUTDOOR scenario the distance increased by $69 \%$ as compared to INDOOR1.

Table (12-a). Cost hata 231 model-3.5GHZ- Urban environment-Indoor1

\begin{tabular}{|c|c|c|}
\hline Parameters & $\begin{array}{l}\text { Maximum Distance } \\
\text { To base station } \mathbf{d}[\mathbf{k m}]\end{array}$ & $\begin{array}{c}\text { Pathloss (d B) } \\
\text { Indoor1 [Thick Wall] }\end{array}$ \\
\hline QPSK CTC $1 / 2$ & 0.0879 & 111.6320 \\
\hline QPSK CTC 3/4 & 0.0810 & 110.3929 \\
\hline 16-QAM CTC 1/2 & 0.0746 & 109.1423 \\
\hline 16-QАМ СТC $3 / 4$ & 0.0665 & 107.4032 \\
\hline 64-QAM CTC $2 / 3$ & 0.0555 & 104.6526 \\
\hline 64-QАM CTC 3/4 & 0.0504 & 103.1642 \\
\hline $\begin{array}{l}\text { Table (12-b). Cost } \\
\text { environment-Indoor1 }\end{array}$ & $\begin{array}{l}t \text { hata } 231 \text { model } \\
1\end{array}$ & GHZ- (SubUrban/Rural) \\
\hline Parameters & $\begin{array}{l}\text { Maximum Distance } \\
\text { To base station d[km] }\end{array}$ & $\begin{array}{l}\text { Pathloss(d B) Indoor1 } \\
\text { [Thick Wall] }\end{array}$ \\
\hline QPSK CTC 1/2 & 0.1075 & 111.6320 \\
\hline QPSK CTC 3/4 & 0.0991 & 110.3929 \\
\hline 16-QAM CTC1/2 & 0.0913 & 109.1423 \\
\hline 16-QAM CTC $3 / 4$ & 0.0814 & 107.4032 \\
\hline 64-QAM CTC 2/3 & 0.0680 & 104.6526 \\
\hline 64-QAM CTC 3/4 & 0.0616 & 103.1642 \\
\hline
\end{tabular}

Table (13-a). Cost hata 231 model-3.5GHZ- (Urban) environmentIndoor 2

\begin{tabular}{ccc}
\hline Parameters & $\begin{array}{c}\text { Maximum } \\
\text { Distance To base } \\
\text { station d[km] }\end{array}$ & $\begin{array}{c}\text { Pathloss(d B) Indoor2 } \\
\text { [Thick Wall and Thin } \\
\text { Wall] }\end{array}$ \\
\hline QPSK CTC 1/2 & 0.0780 & 109.8200 \\
QPSK CTC 3/4 & 0.0719 & 108.5809 \\
16-QAM CTC1/2 & 0.0662 & 107.3303 \\
16-QAM CTC 3/4 & 0.0591 & 105.5912 \\
64-QAM CTC 2/3 & 0.0493 & 102.8406 \\
64-QAM CTC 3/4 & 0.0447 & 101.3522 \\
\hline
\end{tabular}

Table (13-b). Cost hata 231 model-3.5GHZ- (SubUrban/Rural) environment-Indoor 2

\begin{tabular}{ccc}
\hline Parameters & $\begin{array}{c}\text { Maximum Distance } \\
\text { To base station } \\
\mathbf{d}[\mathbf{k m}]\end{array}$ & $\begin{array}{c}\text { Pathloss(d B) Indoor2 } \\
\text { [Thick Wall and Thin } \\
\text { Wall] }\end{array}$ \\
\hline QPSK CTC 1/2 & 0.0954 & 109.8200 \\
QPSK CTC 3/4 & 0.0880 & 108.5809 \\
16-QAM CTC1/2 & 0.0810 & 107.3303 \\
16-QAM CTC 3/4 & 0.0723 & 105.5912 \\
64-QAM CTC 2/3 & 0.0603 & 102.8406 \\
64-QAM CTC 3/4 & 0.0547 & 101.3522 \\
\hline
\end{tabular}

Table (14-a) Cost hata 231 model-3.5GHZ- (Urban) environment-Indoor3

\begin{tabular}{lll}
\hline Parameters & $\begin{array}{l}\text { Maximum Distance } \\
\text { To base station d }[\mathbf{k m}]\end{array}$ & $\begin{array}{l}\text { Pathloss(d B) Indoor3 } \\
\text { [ 2 Thick Wall ] }\end{array}$ \\
\hline QPSK CTC 1/2 & 0.0511 & 103.3962 \\
QPSK CTC 3/4 & 0.0471 & 102.1571 \\
16-QAM CTC1/2 & 0.0434 & 100.9065 \\
16-QAM CTC 3/4 & 0.0387 & 99.1674 \\
64-QAM CTC 2/3 & 0.0323 & 96.4168 \\
64-QAM CTC 3/4 & 0.0293 & 94.9284 \\
\hline
\end{tabular}

Table (14-b). Cost hata 231 model-5MHZ -3.5GHZ- (SubUrban/Rural) environment-Indoor 3

\begin{tabular}{ccc}
\hline Parameters & $\begin{array}{c}\text { Maximum Distance } \\
\text { To base station d[km] }\end{array}$ & $\begin{array}{c}\text { Pathloss(d B) } \\
\text { Indoor3 } \\
\text { [ 2 Thick Wall ] }\end{array}$ \\
\hline QPSK CTC 1/2 & 0.0626 & 103.3962 \\
QPSK CTC 3/4 & 0.0577 & 102.1571 \\
16-QAM CTC1/2 & 0.0531 & 100.9065 \\
16-QAM CTC3/4 & 0.0474 & 99.1674 \\
64-QAM CTC2/3 & 0.0396 & 96.4168 \\
64-QAM CTC3/4 & 0.0359 & 94.9284 \\
\hline
\end{tabular}


Table (15-a). Cost hata 231 model-3.5GHZ- Urban environment- outdoor

\begin{tabular}{ccc}
\hline Parameters & $\begin{array}{c}\text { Pathloss(d B) } \\
\text { outdoor }\end{array}$ & $\begin{array}{c}\text { Distance } \\
(\mathbf{k m})\end{array}$ \\
\hline QPSK CTC 1/2 & 129.6561 & 0.2872 \\
QPSK CTC 3/4 & 128.4170 & 0.2647 \\
16-QAM CTC1/2 & 127.1664 & 0.2438 \\
16-QAM CTC 3/4 & 125.4273 & 0.2175 \\
64-QAM CTC 2/3 & 122.6767 & 0.1815 \\
64-QAM CTC 3/4 & 121.1883 & 0.1646 \\
\hline
\end{tabular}

Table (15-b). Cost hata 231 model-3.5GHZ- (SubUrban/Rural) environment- outdoor

\begin{tabular}{ccc}
\hline Parameters & $\begin{array}{c}\text { Pathloss(d B) } \\
\text { outdoor }\end{array}$ & Distance (km) \\
\hline QPSK CTC 1/2 & 129.6561 & 0.3514 \\
QPSK CTC 3/4 & 128.4170 & 0.3239 \\
16-QAM CTC1/2 & 127.1664 & 0.2983 \\
16-QAM CTC 3/4 & 125.4273 & 0.2661 \\
64-QAM CTC 2/3 & 122.6767 & 0.2221 \\
64-QAM CTC 3/4 & 121.1883 & 0.2014 \\
\hline
\end{tabular}

The results in Tables 12, 13, 14, compars OUTDOOR, INDOOR1, INDOOR 2 and INDOOR 3 scenarios, it is observed that an increase in the maximum cell radius in OUTDOOR model causes increased path loss so, the path loss in QPSK CTC 1/2 for example is reached to 129.6561 $\mathrm{dB}$, as compared to $103.3962 \mathrm{~dB}, 109.8200 \mathrm{~dB}$ and $111.6320 \mathrm{~dB}$ in INDOOR3, INDOOR 2, and INDOOR 1 respectively.

While the maximum cell radius in OUTDOOR model is reached to $0.3514 \mathrm{~km}$ in QPSK CTC $1 / 2$ as compared to $0.0626 \mathrm{~km}, 0.0954 \mathrm{~km}$, and $0.1075 \mathrm{~km}$ in INDOOR3, INDOOR 2, and INDOOR 1 respectively. As expected, if the system data rate is reduced, the cell radius is increased.

The variation of the Power received as a function of the distance to the BS has been computed using equations 8 , 10, and the parameters given in Tables $7-a, 7-b, 8,9$, for the propagation scenarios (OUTDOOR; INDOOR 1, INDOOR 2 and INDOOR 3 ) in the cases of urban and suburban at frequency band $3.5 \mathrm{GHZ}$, and the results are shown in figures 5- 8

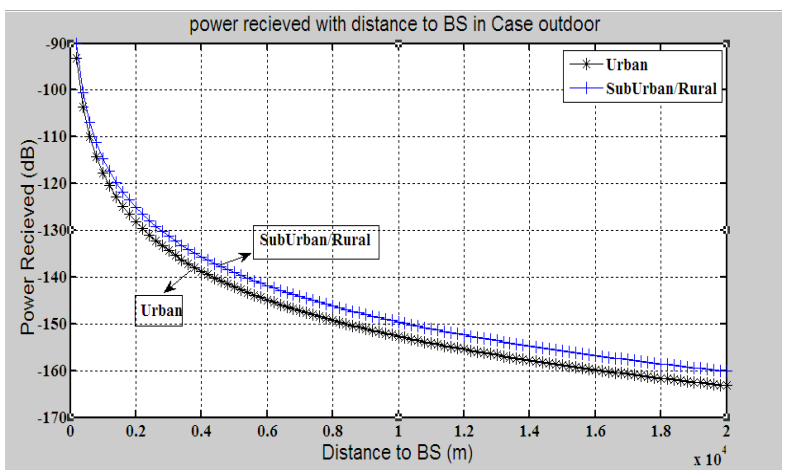

Figure 5 Power received with distance to BS (COSTHATA) in case outdoor

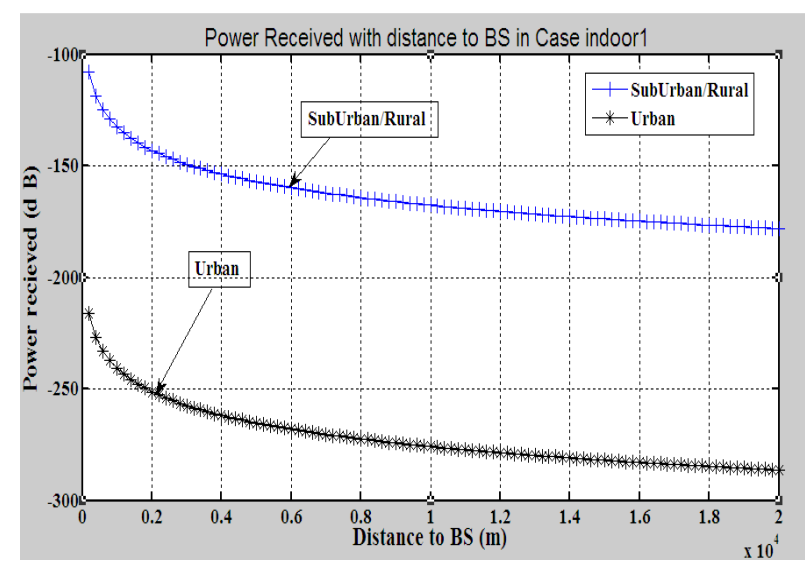

Figure 6. Power received with distance to BS (COSTHATA) in case indoorl

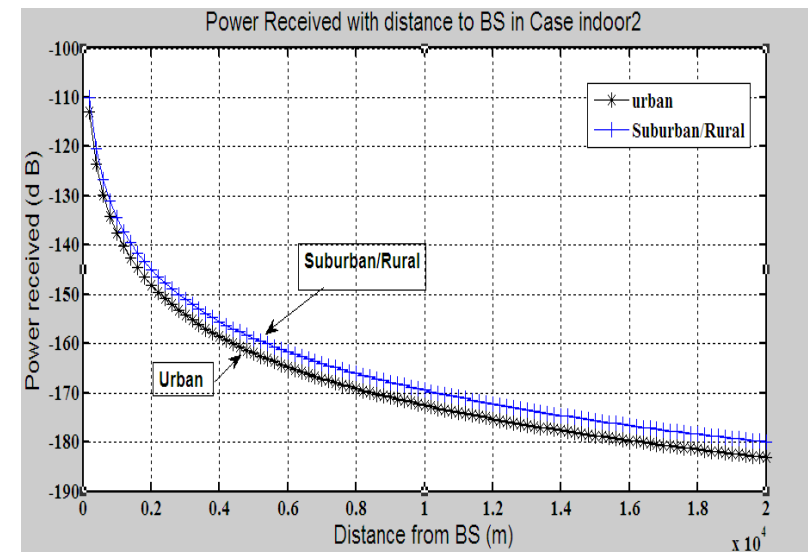

Figure 7. Power received as a function of distance to BS (COSTHATA) in case indoor 2

The results in figures 5-8 showed that the maximum power received in the suburban case is increased by $100 \%$, $3 \%, 2.5 \%$, and $4 \%$ for INDOOR1, INDOOR2, INDOOR3, and OUTDOOR respectively as compared to the urban case.

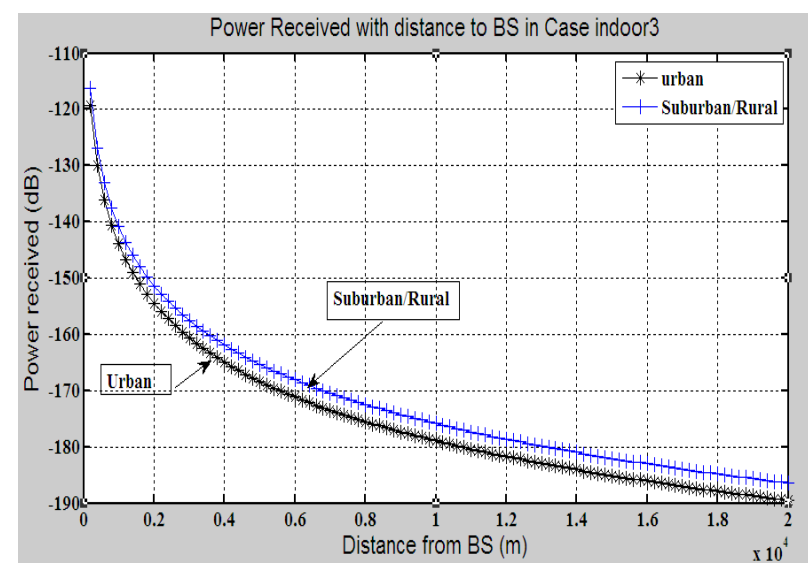

Figure 8. Power received with distance to BS (COSTHATA) in case indoor3

Comparing OUTDOOR, INDOOR1, INDOOR 2 and INDOOR 3 scenarios it is noticed that the increase in the maximum power received is $-90 \mathrm{~dB}$ in OUTDOOR 
(suburban case), as compared to $-100 \mathrm{~dB},-110 \mathrm{~dB}$, and $120 \mathrm{~dB}$ in INDOOR 1, INDOOR 2, and INDOOR 3 respectively.

While, in urban case the maximum power received is -92 $\mathrm{dB}$ in OUTDOOR, as compared to $-220 \mathrm{~dB},-110 \mathrm{~dB}$, and $120 \mathrm{~dB}$ in INDOOR 1, INDOOR 2, and INDOOR 3 respectively.

\section{Conclusions}

Propagation models are used extensively in network planning, particularly for conducting feasibility studies and during initial deployment. They are also very useful for performing interference studies as the deployment proceeds. Knowledge on signal degradation enables RF designers to determine the required field strength for a reliable coverage in a specific area.

In this paper, the data rate for the downlink of OFDMAbased IEEE $802.16 \mathrm{~m}$ WiMAX system and the available DL throughput as a function of distance to the Base Station (BS) are estimated for a number of propagation scenarios (OUTDOOR; INDOOR 1, INDOOR 2 and INDOOR 3). Moreover, Walls penetration loss is also considered. Adaptive modulation and Coding (AMC) schemes were assumed in the present study for $5 \mathrm{MHz}$ and $20 \mathrm{MHz}$ channel bandwidth.

Three indoor scenarios have then been considered. These are representing with the respective attenuations calculated by equations (1) and (2) for a $3.5 \mathrm{GHz}$ frequency. The chosen Indoor scenarios try to represent possible limiting situations on propagation. The analysis was limited to two walls, since when the number of walls increases, other propagation mechanisms become dominant. The effects of the number of wall, and construction materials for each scenario were considered.

The results showed that the maximum distance to base station in the suburban case is increased by $22 \%, 22.3 \%$, $22.5 \%$, and $18.5 \%$ for INDOOR1, INDOOR2, INDOOR3, and OUTDOOR respectively as compared to the urban case.

In OUTDOOR case, the cell range increased as compared to INDOOR 1, INDOOR 2 and INDOOR 3 . It is observed that the maximum distance to base station in INDOOR 2 increased by $34.4 \%$ more than INDOOR 3, where in INDOOR1 this distance increase by $11.3 \%$ comparing INDOOR2, where without any Penetration Loss in OUTDOOR scenario this distance increase by $69 \%$ comparing INDOOR1.

While the maximum cell radius in OUTDOOR model is reached to $0.3514 \mathrm{~km}$ in QPSK CTC $1 / 2$ as compared to $0.0626 \mathrm{~km}, 0.0954 \mathrm{~km}$, and $0.1075 \mathrm{~km}$ in INDOOR3, INDOOR 2, and INDOOR 1 respectively. As expected, decreasing the system data rates, the cell radius is slightly increased.

Comparing OUTDOOR, INDOOR1, INDOOR 2 and INDOOR 3 scenarios it is observed that increase in the maximum power received is $-90 \mathrm{~dB}$ in OUTDOOR (suburban case), as compared to $-100 \mathrm{~dB},-110 \mathrm{~dB}$, and $120 \mathrm{~dB}$ in INDOOR 1, INDOOR 2, and INDOOR 3 respectively. While, in (urban case) the maximum power received is $-92 \mathrm{~dB}$ in OUTDOOR, as compared to $-220 \mathrm{~dB}$, $-110 \mathrm{~dB}$, and $-120 \mathrm{~dB}$ in INDOOR 1 , INDOOR 2, and INDOOR 3 respectively.

In INDOOR 3 case the maximum distance to base station and the maximum power received is decreased as compared to INDOOR 2, INDOOR 1 due to the construction materials for each scenario.

At $20 \mathrm{MHz}$ bandwidth one can observe an increasing in data rate as compared to the $5 \mathrm{MHZ}$ bandwidth.

\section{References}

[1] Garber, L, "Mobile WiMAX: The Next Wireless Battle Ground", IEEE Computer Society, Jun. 2008, vol. 41, No. 6, p p16-18.

[2] "WiMAX Forum Mobile System Profile, Release 1.0 approved specification, Revision 1.4.0", WiMAX Forum, 2007.

[3] H. Yaghoobi, "Scalalable OFDMA Physical Layer in IEEE802.16Wireless MAN", Intel Technology Journal, August 2004, Vol 08, pp. 201-212.

[4] J. G. Andrews, A. Ghosh, R. Muhamed, "Fundamentals of WiMAX", Prentice Hall, New York, 2007.).

[5] IEEE Computer Society \& IEEE Microwave Theory and Techniques Society, "IEEE Std $802.16 \mathrm{e}^{\mathrm{TM}}-2005$ : IEEE Standard for Local and metropolitan area networks - Part 16: Air Interface for Fixed and Mobile Broadband Wireless Access Systems; Amendment 2: Physical and Medium Access Control Layers for Combined Fixed and Mobile Operation in Licensed Bands", IEEE, 2005.

[6] COST 231, Digital mobile radio towards future generation systems, Final Report, COST Telecom Secretariat, European Commission, Brussels, Belgium, 1999.

[7] M. Hata, "Empirical formula for propagation loss in land mobile radio services", IEEE Transactions on Vehicular Technology, September 1981, vol. 29, pp. 317-325.

[8] L. M. Correia (Ed.), "Wireless Flexible Personalized Communications", Wiley, Chichester, 2001.

[9] P. Nobles, "A comparison of indoor pathloss measurements at $2 \mathrm{GHz}, 5 \mathrm{GHz}, 17 \mathrm{GHz}$ and $60 \mathrm{GHz}$ ", COST 259, TD(99)100, Leidschendam, The Netherlands,September 1999.

[10] Doug, G., "Mobile WiMAX - part I: A technical overview and performance evaluation," WiMAX Forum, 2006.

[11] Ahmadzadeh, A. M. "Capacity and Cell-Range Estimation for Multitraffic Users in Mobile WiMAX" MSc. Dept. of Electrical ,Communication and Signal Processing Engineering , University College of Borås School of Engineering Sept. 2008.

[12] Koon Hoon Teo., Zhifeng Tao., and Jinyun Zrang. "The Mobile Broadband Standard" IEEE Signal Processing Magazine, September 2007. 
[13] Hala. B. Nafea, Fayez W. Zaki," PERFORMANCE OF IEEE $802.16 \mathrm{~m}$ WIMAX USING ADAPTIVE MODULATION AND CODING" The Mediterranean Journal of Electronics and Communications, Vol. 7, No. 2, 2011

\section{Biography}

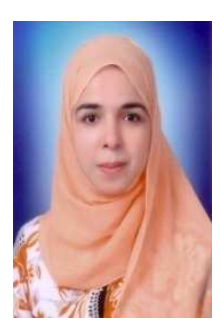

Hala B. Nafea has received the B.Sc. and M.Sc. degrees from the Department of Electronics and Communications Eng., Faculty of Engineering, Mansoura University. She is now a Ph.D. student at the same Department. Moreover, she is a lecturer assistant at the Higher Institute of Engineering and Technology, Mansoura, EGYPT. Her research interest is in the area of Mobile Communications.

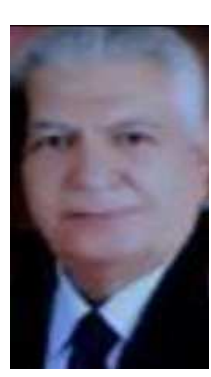

Fayez Wanis Zaki, B.Sc., M.Sc. and Ph.D. is a professor at the Department of Electronics and Communications Eng., Faculty of Engineering, Mansoura University, EGYPT. His main research interests are: Digital Communications, Mobile Communications, Communications Networks, Speech and Image processing. He is with the Department of Electronics and Communications Eng., Faculty of Engineering, Mansoura University, EGYPT since 1969. He received his Ph.D. from Liverpool University in 1982 . He supervised several M.Sc. and Ph.D. theses. He is now a member of the professorship promotion committee in Egypt.

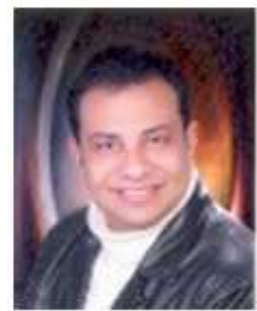

Hossam E. S. Moustafa, B.Sc., M.Sc. and Ph.D., is a lecturer at the Dept. of Electronics and Communication Eng., Faculty of Engineering, Mansoura University, Egypt. His main research interests are: Communications Networks, and Speech and Image processings. 